\title{
Cinzas Volantes Aplicações em Cimentos e Betões
}

CPPE*

As cinzas volantes são um produto residual da queima do carvão pulverizado nas caldeiras das centrais termoeléctricas. No seu estado seco, tal como são recolhidas nos precipitadores electrostáticos, têm uma textura e cor semelhante à do cimento, sendo constituídas, essencialmente, por partículas esféricas muito finas, compostas principalmente por silico-aluminatos. Nos últimos anos têm-se realizado estudos exaustivos sobre a aplicação das cinzas volantes, que levam à conclusão de que estas podem ser utilizadas com grandes vantagens em diversas indústrias. Têm no entanto que obedecer a especificações adequadas no que se refere à sua composição e grau de finura. Este texto é especialmente dedicado às aplicações das cinzas volantes, resultantes da queima de carvão betuminoso, no cimento e no betão. Nestas áreas, as cinzas volantes oferecem benefícios substanciais, existindo já em Portugal vários exemplos de obras importantes que bem demonstram os benefícios da sua aplicação.

Finalmente realça-se o facto da aplicação das cinzas volantes contribuir para minimizar o impacte ambiental com a deposição dos resíduos da queima de carvão e com a redução do volume de escavações, em pedreiras, necessário ao fabrico de cimento. Uma tonelada de cinza utilizada em substituição do cimento, corresponde ainda à economia de energia equivalente a cerca de $100 \mathrm{~kg}$ de fuelóleo (400 kWh).

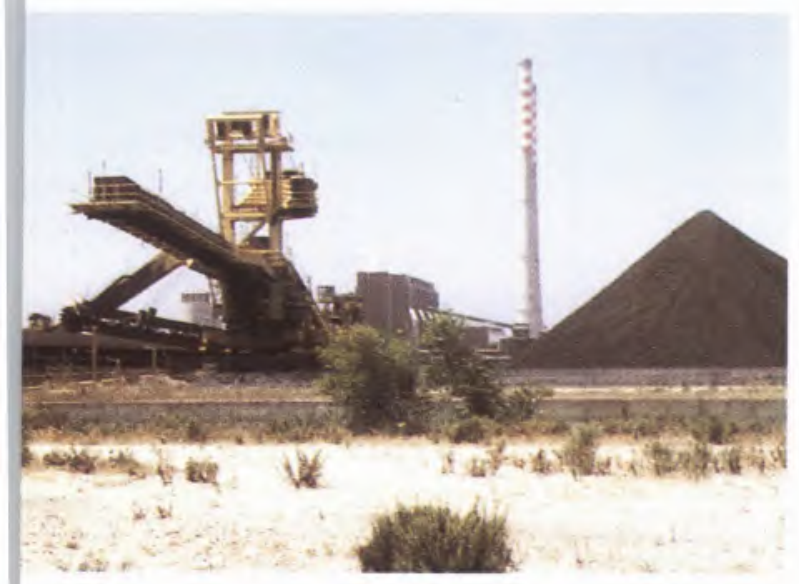

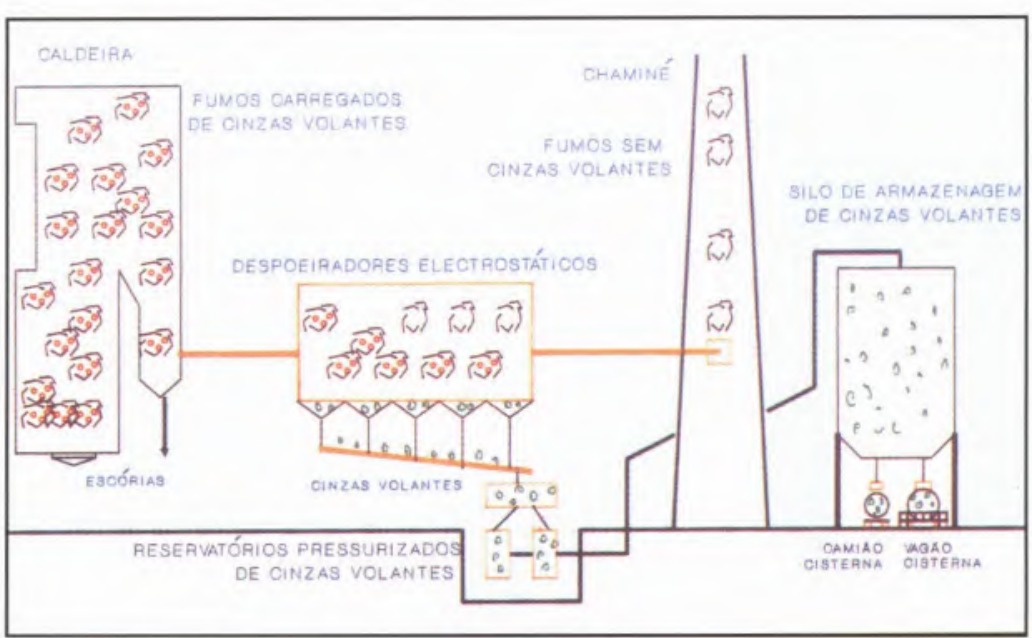

\section{PROCESSO INDUSTRIAL}

A composição das cinzas volantes depende do tipo de carvão que é queimado nas caldeiras. Nas centrais termoeléctricas, o carvão normalmente utilizado é do tipo betuminoso, adquirido no mercado internacional.

0 carvão é recebido em navios no Porto de Sines e transportado para a central termoeléctrica de Sines, por telas transportadoras.

0 carvão armazenado em pilhas em parque é retirado pela máquina de retoma e segue por meio de tapetes transportadores, em várias alternativas de alimentação, para os silos situados junto aos geradores de vapor. É seguidamente enviado através dos alimentadores para os moinhos onde é seco e pulverizado finamente e misturado com 0 ar insuflado para os queimadores, assegurando-se uma combustão à temperatura de aproximadamente $1300^{\circ} \mathrm{C}$.

Para evitar a degradação do ambiente, que seria provocada pelas cinzas emitidas na atmosfera, fazem-se passar os gases de combustão, carregados de cinzas, no seu trajecto para a chaminé, através de despoeiradores do tipo precipitadores electrostáticos, de elevado rendimento onde são retidas mais de $99 \%$ do peso total das partículas, dando origem às chamadas cinzas volantes. Depois de recolhidas nos despoeiradores, estas cinzas passam aos reservatórios de pressurização e são conduzidas, por via pneumática para os silos princi- pais ou de arranque conforme se trate de cinzas com qualidade para comercialização ou não.

Das cinzas produzidas na laboração da central, cerca de $85 \%$ correspondem a cinzas volantes e com potencialidade de utilização pela indústria do cimento e do betão, os silos principais estão equipados para poderem carregar ou camiões cisterna ou vagões de caminho de ferro. Por razões ambientais estão providos de sistemas especiais de despoeiramento.

As cinzas (volantes e escórias) que não puderem ser utilizadas pela indústria, são humedecidas e transportadas para o parque de cinzas. Este local foi previamente preparado com isolamento do solo por uma membrana impermeável a fim de evitar que as águas subterrâneas sejam contaminadas pelas águas pluviais. Estas, por sua vez, são drenadas para uma bacia de decantação, onde são tratadas. Para evitar o levantamento das cinzas pela acção do vento, estas são espalhadas, compactadas e regadas periodicamente por um sistema de aspersão de água. No seu estádio final são cobertas com uma camada de terra arável aonde são plantadas várias espécies vegetais características da zona.

\section{CINZAS VOLANTES Características}

As cinzas volantes apresentam propriedades pozolânicas, isto é, na presença de água têm a propriedade de fixar 


\begin{tabular}{|c|c|c|}
\hline & Caracteristicas Físicas & Valores \\
\hline - Forma e estado da superfície dos grãos & $\begin{array}{l}\text { - pó fino } \\
\text { - de cor cinzenta } \\
\text { - macio ao tacto } \\
\text { - semelhante à do cimento }\end{array}$ & - \\
\hline • Observação microscópica & $\begin{array}{l}\text { - apresentam-se sob a forma de esferas cheias ou porosas, } \\
\text { vitreas, isoladas ou aglomeradas, chamadas cenosferas. }\end{array}$ & - \\
\hline • Finura & $\begin{array}{l}\text { - granulometria ( } \mu \mathrm{m}) \\
\text { - residuo no peneiro de } 45 \mu \mathrm{m}(\%) \\
\text { - superficie especifica }\left(\mathrm{m}^{2} / \mathrm{kg}\right)\end{array}$ & $\begin{array}{r}0,5 \\
25 \\
280 \\
\end{array}$ \\
\hline • Humidade & - em silos (\% em peso sobre produto seco) & $<1$ \\
\hline • Massa volúmica & - real $\left(\mathrm{kg} / \mathrm{dm}^{3}\right)$ & 2,3 \\
\hline • Índice de actividade pozolânica & - substituição até 50\% com cimento Portland normal, aos 28 dias (\%) & $>75$ \\
\hline - Expansibilidade & $\begin{array}{l}\text { - substituição de 30\% com cimento Portland normal em relação à das } \\
\text { pastas padrão. }\end{array}$ & 0,8 \\
\hline
\end{tabular}

0 cálcio com formação de silicatos e aluminatos de cálcio, compostos estes semelhantes aos dos obtidos nas reacções de hidratação de cimento Portland.

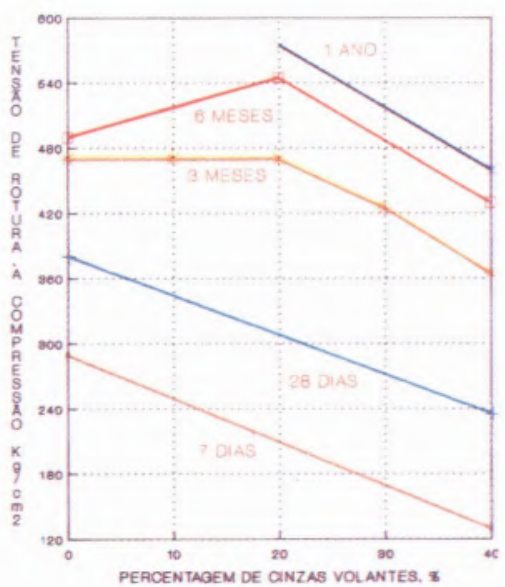

Os ensaios químicos efectuados sobre diversas argamassas e pastas de cimento com incorporação de cinzas volantes obtidas com os vários tipos de carvão apresentam um índice de pozolanicidade elevado. Por outro lado, os ensaios físicos realizados, sobre as mesmas pastas e argamassas, evidenciam valores do índice de actividade pozolânica elevados, quer quando referidos a resistências à compressão, quer em resistências à tracção por flexão. Apresentam-se os resultados encontrados com substituição de 20 a $40 \%$ de cimento por cinzas volantes.

As cinzas volantes, têm como elementos predominantes o silício, aluminio e ferro que, na forma de óxidos representam 70 a $90 \%$ da sua composição. Apresentam ainda outros elementos

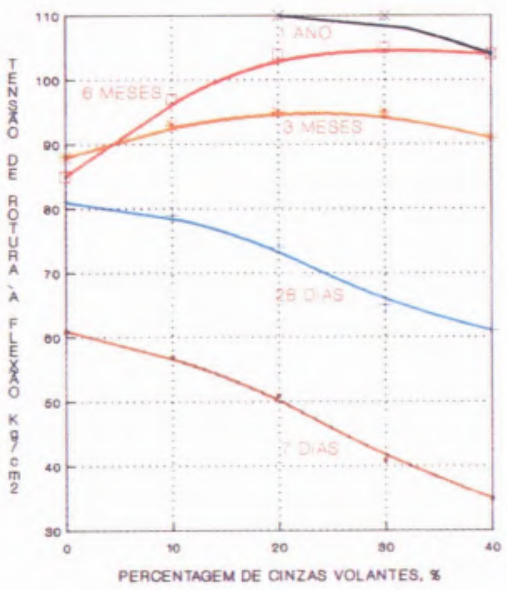

e carbono não queimado em percentagens variáveis com o tipo de carvão e condições de queima.

\begin{tabular}{|c|c|c|}
\hline \multicolumn{2}{|c|}{$\begin{array}{l}\text { COMPOSIÇÃO QUIMICA } \\
\text { Constituintes maiores } \\
\text { e menores }\end{array}$} & $\begin{array}{r}\text { VALORES MÉDIOS } \\
(\%)\end{array}$ \\
\hline Silica & $\left(\mathrm{SiO}_{2}\right)$ & 52 \\
\hline Aluminio & $\left(\mathrm{Al}_{2} \mathrm{O}_{3}\right)$ & 29 \\
\hline Ferro & $\left(\mathrm{Fe}_{2} \mathrm{O}_{3}\right)$ & 8,5 \\
\hline Cálcio & $(\mathrm{CaO})$ & 4,5 \\
\hline Magnésio & $(\mathrm{MgO})$ & 1,2 \\
\hline Titânio & $\left(\mathrm{TiO}_{2}\right)$ & 1.9 \\
\hline Fósforo & $\left(\mathrm{P}_{2} \mathrm{O}_{5}\right)$ & 0,3 \\
\hline Sódio & $\left(\mathrm{Na}_{2} \mathrm{O}\right)$ & 0,5 \\
\hline Potássio & $\left(\mathrm{K}_{2} \mathrm{O}\right)$ & 1,0 \\
\hline Sulfatos & $\left(\mathrm{SO}_{3}\right)$ & 0,7 \\
\hline Cloretos & (Cl-) & 0,01 \\
\hline Manganês & $(\mathrm{MnO})$ & 0,02 \\
\hline Cobre & (Cu) & 0,037 \\
\hline Zinco & $(\mathrm{Zn})$ & 0,015 \\
\hline Cádmio & (Cd) & 0,001 \\
\hline Niquel & (Ni) & 0,026 \\
\hline Chumbo & $(\mathrm{Pb})$ & 0.008 \\
\hline Crómio & $(\mathrm{Cr})$ & 0.015 \\
\hline Mercúrio & $(\mathrm{Hg})$ & 0,027 \\
\hline Cal livre & $(\mathrm{CaO})$ & 0,02 \\
\hline Perda ao fo & & $<5$ \\
\hline
\end{tabular}

No entanto, os valores de inqueimados detectados nas diversas amostras de cinzas colhidas, são inócuos para betão e perfeitamente admissiveis segundo a diversa literatura existente.

COMPOSIÇÃO QUIMICA COMPARADA

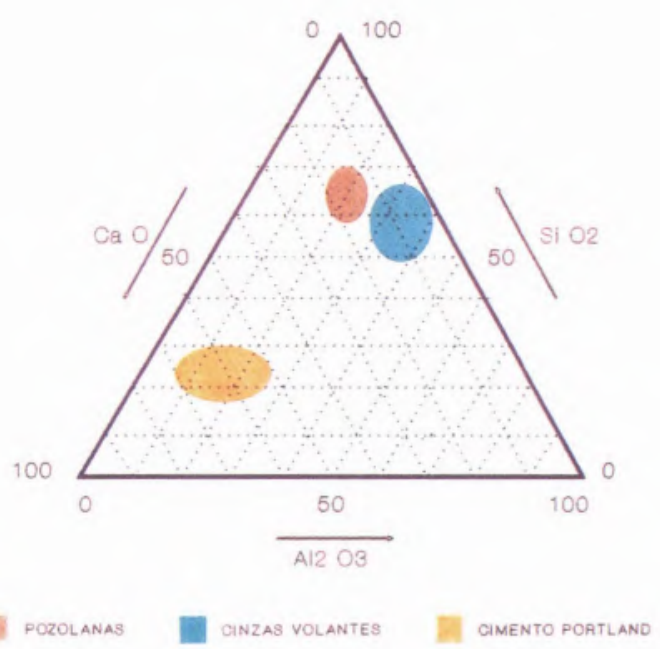

CONTROLE DE QUALIDADE

As cinzas volantes secas constituem-se, na realidade, como uma verdadeira matéria prima utilizável em variadas e interessantes aplicações técnicas o que justifica a efectiva adopção de adequados sistemas de controle das suas características físico-químicas não só no processo da sua produção como nas fases do transporte, armazenagem e sua entrega aos clientes.

Existem constituintes, tais como os sulfatos, cloretos, magnésio e cálcio livre, cujas concentrações são limitativas nas aplicações das cinzas, no entanto, com os 


\begin{tabular}{|c|c|c|c|c|c|}
\hline \multicolumn{2}{|l|}{ Constituintes/características } & $\begin{array}{c}\text { BS } 3892 \\
\text { Part } 1\end{array}$ & $\begin{array}{c}\text { ASTM } \\
618\end{array}$ & $\begin{array}{l}\text { EN } \\
450\end{array}$ & $\begin{array}{l}\text { Cinzas } \\
\text { Sines }\end{array}$ \\
\hline Humidade & \% máx. & 0.5 & 3 & - & $<0,1$ \\
\hline Perda ao fogo & \% máx. & 7 & 6 & 5 & $1,5-4.5$ \\
\hline $\mathrm{SiO}_{2}+\mathrm{Al}_{2} \mathrm{O}_{3}+\mathrm{Fe}_{2} \mathrm{O}_{3}$ & $\%$ min. & - & 70 & - & $70-90$ \\
\hline $\mathrm{MgO}$ & \% máx. & 4 & - & - & $0,3-2$ \\
\hline $\mathrm{SO}_{3}$ & \% máx. & 2,5 & 5 & 3 & $0,2-1$ \\
\hline Cloretos & $\%$ máx. & - & - & 0,1 & $<0,01$ \\
\hline $\mathrm{CaO}$ livre & \% máx. & - & - & 1 & $<0,1$ \\
\hline $\begin{array}{l}\text { Finura - Quantidade retida } \\
\text { no peneiro de } 45 \mu \mathrm{m}\end{array}$ & \% máx. & 12,5 & 34 & 40 & 25 \\
\hline
\end{tabular}

tipos de carvões queimados nas centrais, estes valores encontram-se dentro dos limites aceites internacionalmente. A perda ao fogo é igualmente um parâmetro limitativo para o uso das cinzas, mas apresentando também valores aceitáveis devido a uma cuidadosa selecção das cinzas destinadas à comercialização.

As características das cinzas volantes comercializadas pela EDP são assim rigorosamente controladas e obedecem a normas internacionais de qualidade.

Com a finalidade de se controlar a qualidade das clnzas que se produzem, existe um sistema de recolha contínua de amostras para análise, nos reservatórios de pressurização da cinza, e em cada turno de 8 horas é feita uma amostragem para análise de perda ao fogo e humidade. Para controlar a qualidade das cinzas volantes secas fornecidas, obtêm-se na operação de carga, uma amostra diária, constituída a partir das amostras recolhidas nos veículos carregados, a qual é dividida em duas partes aproximadamente iguais. Uma delas é submetida a determinação da humidade e perda ao fogo.

A segunda amostra diária é guardada após conveniente referenciação dos veículos ou composições, tonelagem, data e hora de carregamento na central para servir de amostra testemunho.

Numa amostra mensal constituída a partir das amostras diárias de cinzas volantes, determinam-se as características físico-químicas de maior relevância para a utilização destas na indústria dos cimentos e dos betões.
Permitem a obtenção de baixos custos de manutenção do equipamento (betoneiras e bombas) pelos efeitos lubrificantes das partículas esféricas (cenosferas) das cinzas.

Verifica-se aumento das resistências físico-mecânicas, a diversas idades, devido ao índice de actividade pozolânica. hidratação, com a consequente redução de fissuração, sem quebras significativas de resistências a idades jovens do betão (inferiores a 3 dias).

Há aumento da plasticidade do betão, 0 que permite reduzir a relação água / cimento para uma mesma plasticidade, com as consequências benéficas de:

- aumento da resistência mecânica

- dimuinuição da retraç̧ão hidráulica

- redução da fissuração

Dá-se 0 aumento da compacidade do betão, melhorando a resistência à agressividade do meio.

Depois da descofragem as superficies à vista apresentam melhor aspecto resultante do melhoramento da textura devido às partículas das cinzas.

\section{APLICAÇÕES}

Empregaram-se em blocos de betão no Terminal do Porto de Sines com 0 peso de 60 toneladas cada. A utilização das cinzas aumentou a compacidade do betão, resistindo este mais facilmente à agressividade do ambiente.

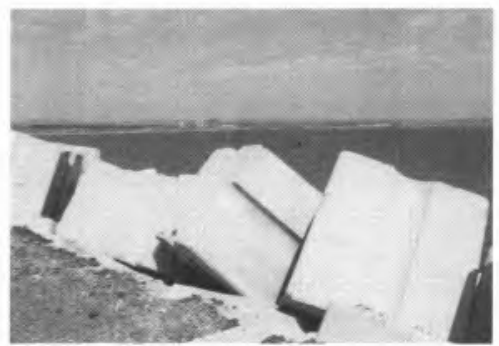

É notável a redução do calor de ambiente (atues á entes poluídos).

\section{VANTAGENS DA UTILIZAÇÃO DAS CINZAS VOLANTES NOS}

As cinzas apresentam pozolanicidade elevada, 0 que confere ao betão com elas fabricado um aumento de resistência aos ataques químicos do

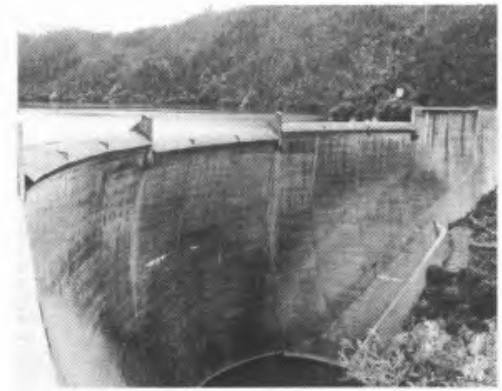

Troço da Via do Infante, Algarve, onde foram utilizadas cinzas no betão da camada de desgaste.

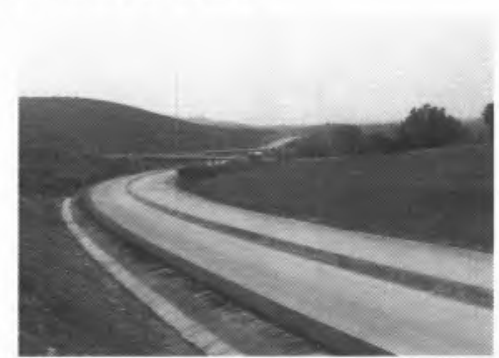

0 emprego de cinzas nos betões das barragens diminui a sua porosidade e reduz significativamente 0 calor de hidratação na betonagem de grandes volumes de betão.

Já utilizadas na reparação da barragem da Bouçã, as cinzas volantes vão ser utilizadas na construção da barragem de Foz-Côa, numa quantidade estimada em 100 mil toneladas.

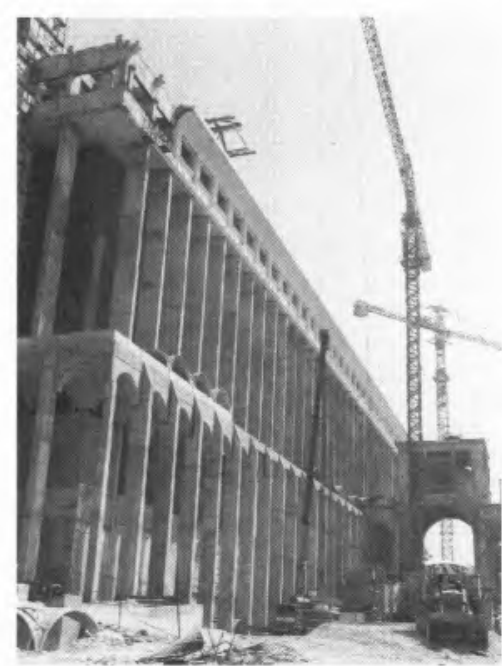

Betão incorporando parcialmente cinzas foi utilizado neste edifício.

${ }^{\star}$ CPPE, Companhia Portuguesa de Produção de Electricidade, $S A$ (Grupo EDP) 


\section{Novas possibilidades na deteção HPLC com o novo detector LCD da FISONS}

O novo detector MD 800 LCD (Liquid Chromatography Detector) ; de fácil utilização ; da FISONS, Organic Analyses, não é um detector que só mostra picos como os outros detectores HPLC!

Com base numa tecnologia bem elaborada, o MD 800 LCD faz a identificação positiva dos picos desconhecidos durante uma analise de cromatografia líquida. Desta forma, ganha-se eficiência e diminui o tempo de desenvolvimento de metodos. Com um simples movimento do rato acedemos a todas as informações espectrais de massa.

Com o MD $800 \mathrm{LCD}$, é possível adquirir os dados necessários para a identificação estrutural com bibliotecas digitais ou para a confirmação do peso molecular em ionização química $(\mathrm{CI})$.

O novo detector MD 800 LCD pode ser acoplado a qualquer sistema de HPLC existente bem como a qualquer outro tipo de detector LC normal.

Os limites de detecção são da ordem dos ppb (parte por bilião) e podem ser optimizados no modo ionização quimica para iões negativos.

O MD 800 LCD é controlado pelo sistema de tratamento de dados MASSLAB, em ambiente Windows e utiliza todas as possibilidades actuais deste utilitário.

A manutenção do sistema é muito fácil e pode ser feita pelo utilizador num tempo mínimo de paragem do instumento com assistência do software.

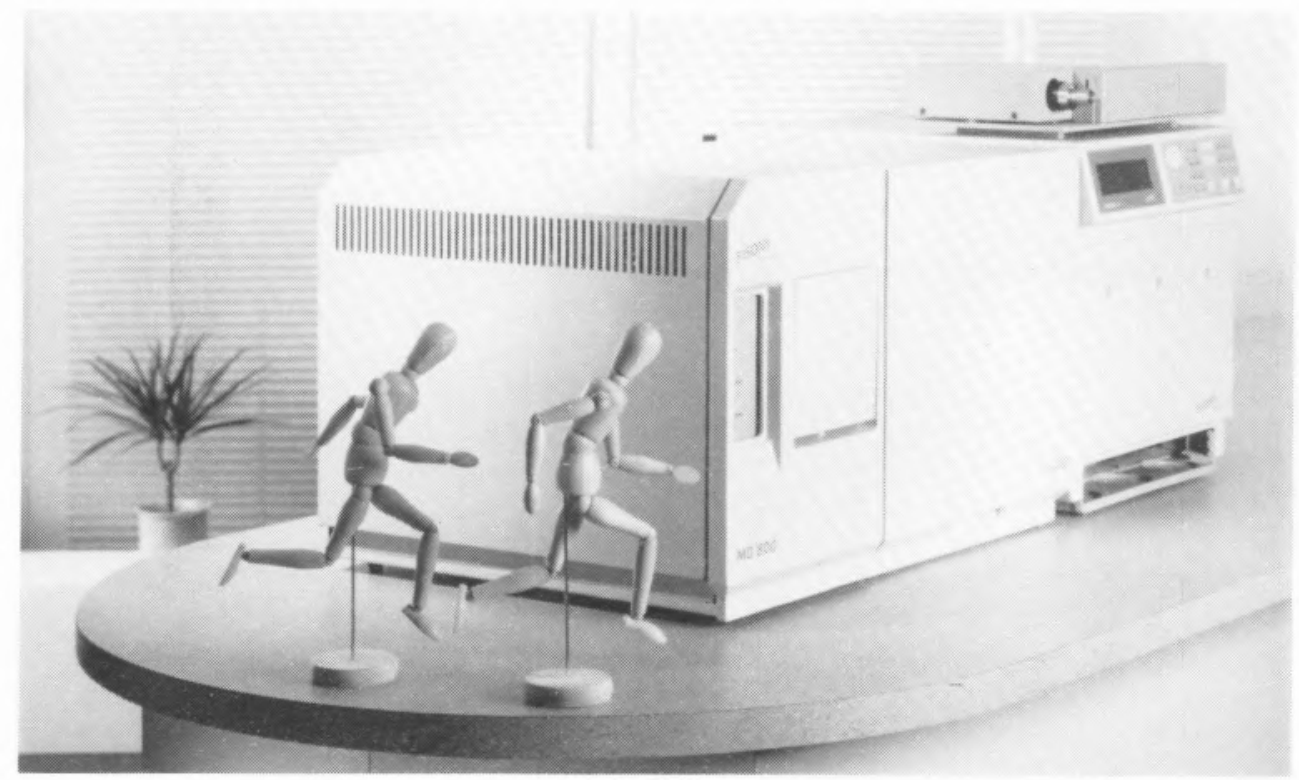

Para mais informações, contactar DIAS de SOUSA Lda. - Núcleo FISONS (01) $9592316 / 9594462$ 